\title{
Polyurethane networks based on disulfide bonds: from tunable multi-shape memory effects to simultaneous self-healing
}

\author{
Xiao-Ying Deng, Hui Xie, Lan Du, Cheng-Jie Fan, Chuan-Ying Cheng, Ke-Ke Yang ${ }^{*}$ and \\ Yu-Zhong Wang
}

\begin{abstract}
With the prompt development in intellectualization nowadays, the smart materials with multifunctionality or multi-responsiveness are highly expected. But it is a big challenge to integrate the different actuating units into a single system in a synergy pattern. Herein, we put forward a new strategy to develop the polyurethane networks which can present shape-memory effect and self-healing effect in independent way as well as simultaneous acting mode. To realize this goal, poly(tetremethylene ether) glycol was chosen as the soft segment to ensure the polymer chains a good mobility, and disulfide bond as the dynamic covalent bond was embedded in the backbone of polyurethane to endow it with desirable self-healing capacity under mild condition. Moreover, a rational control of the architecture of the networks by adjusting the content of disulfide bond and the degree of cross-linking, a broad glass transition temperature $\left(T_{\mathrm{g}}\right)$ was achieved, which enabled the network a versatile shape-memory effect, covering from dual-, triple- so far as to quadrupleshape memory effect. More importantly, the shape recovery and healing process can be realized simultaneously because of the highly matched actuating condition in this system.
\end{abstract}

Keywords: polyurethane network, disulfide bond, self-healing, shape-memory

\section{INTRODUCTION}

With the prompt development in intellectualization nowadays, the smart materials have attracted great attention from both academia and industry. By virtue of the unique advantages of polymer materials, the research on polymeric items such as shape-memory polymers (SMPs) [1-7] and self-healing materials (SHMs) [8-13] is booming up in recent decades. Actually, the material with single-function is hard to fulfill the requirement in some complex environment, so the multifunctional [7] or multi-responsive materials [14] have been highly concerned. How to integrate the different actuating units into a single system with a synergy pattern is a big challenge for the researchers. Herein, we try to establish a new smart material which can present shape-memory effect and self-healing effect in independent way as well as simultaneous acting mode.

To achieve this goal, indeed, a full understanding of mechanism for each unit is needed. As we know, a simple dual-shape memory polymer consists of a molecular switch and a netpoint; the former determines the permanent shape, and the latter is responsible for the shape recovery $[15,16]$. Generally, a thermally-induced SMPs can be easily realized by employing thermal transitions $\left(T_{\text {trans }}\right)$, such as glass transition temperature $\left(T_{\mathrm{g}}\right)$, melting temperature $\left(T_{\mathrm{m}}\right)$ or liquid crystalline clearing temperature $\left(T_{\mathrm{cl}}\right)$ as the molecular switch. To pursue a multishape memory effect, the direct way is to introduce multiple molecular switch into the system; however, this method usually needs a complex preparation process and brings mutual interference. Recently, a simple strategy relying on a single broad thermal transition to achieve multi-shape memory effect has been explored [17-20]. Xie et al. discovered the perfluorosulphonic acid (PFSA) ionomer [18] and V-shaped gradient copolymer of styrene and methyl acrylate [19], which had only one broad reversible phase transition, and exhibited dual-, triple-, and at least quadruple-shape memory effects. In our previous work, we also designed a series of side-chain liquid crystalline polyurethane networks, and considering the overlap of $T_{\mathrm{g}}$ and $T_{\mathrm{cl}}$ as one broad thermal transition,

Center for Degradable and Flame-Retardant Polymeric Materials (ERCEPM-MoE), College of Chemistry, National Engineering Laboratory of EcoFriendly Polymeric Materials (Sichuan), State Key Laboratory of Polymer Materials Engineering, Sichuan University, Chengdu 610064, China

* Corresponding author (email: kkyangscu@126.com) 
a well-controllable gradual recovery effect was achieved [20].

As another class of smart materials, SHMs have the capacity for self-healing and autonomous regeneration when suffering physical damage. From the view of working mechanism, the intrinsic healing strategy based on various reversible bonds or dynamic interactions shows great promise because of the multi-healability to extend the lifetime. Compared with the weak dynamic bonds (such as hydrogen bonding [21-24], $\pi-\pi$ interactions $[25,26]$, host-guest interactions $[27,28])$, strong reversible covalent bonds (such as Diels-Alder bond [2931], disulfide bond [32-38], acylhydrazone bonds [39,40], phenyl boronate complexations $[41,42]$, and imine bonds $[43,44]$ ) endow SHMs with better mechanical performance. Hereinto, disulfide bond shows the proper bonding energy, which ensures the materials to heal under relatively mild condition [32-38]. Canadell et al. [32] used the epoxy matrix containing disulfide links to prepare a rubber network, which achieved mild repair at $60^{\circ} \mathrm{C}$. Lafont et al. [33] synthesized a series of thermoset rubber elastomers containing disulfide bonds, which exhibited cohesive self-healing properties at a modest healing temperature of $65^{\circ} \mathrm{C}$. An et al. [35] prepared dual sulfide-disulfide cross-linked networks which had the rapid self-healing ability at room temperature.

Lately, the research combining the shape-memory effect and self-healing effect has been reported. One representative strategy is the shape-memory assisted selfhealing (SMASH) firstly introduced by Mather's group [45]. They have developed a series of SMASH materials based on poly( $\varepsilon$-caprolactone) (PCL), for example, the SMASH coatings with electrospun thermoplastic poly( $\varepsilon$ caprolactone) (PCL) fibers [46], or SMASH blends incorporating a covalently cross-linked PCL network as a thermoset for shape-memory properties and a linear PCL thermoplastic to provide a self-healing property [47]. Chen et al. [36] also reported a kind of SMASH polyurethane material containing disulfide bond, which can almost regain its mechanical properties upon heating above $80^{\circ} \mathrm{C}$. In our previous work, we have designed a series of shape-memory dynamic work based on Diels -Alder bond [31], metal-ligand coordination [48] and hydrogen bonding [22], which also displayed healing capacity. Among these investigations, the feature of shape memory is actuated separately or acts as an assistant for self-healing. In fact, there exists potentially damaging risk for SMPs in practical application while it has been programmed and just ready for recovery, and how to realize synchronous shape-memory and self-healing is still a challenge.

Herein, we put forward a new strategy to develop polyurethane network, which not only presents tunable shape-memory effects, but also can undergo simultaneous self-healing and shape recovery when it is damaged after programming. The key issue we need to resolve is to realize the simultaneous effect via reasonable structure. For synthetic approach, poly(tetramethylene ether) glycol (PTMEG) was chosen as the soft segment, and isophorone diisocyanate (IPDI) with asymmetric alicyclic structure as the chain extender to produce linear polyurethane prepolymer; meanwhile, disulfide bond was embedded in the backbone, and the cross-linker was added to achieve the target networks (PEUR-SS $x$-Ns). Moreover, by effectively adjusting the composition and cross-linking degree, a broad $T_{\mathrm{g}}$ transition was achieved, which enabled a tunable shape memory performance covering from dual-, triple-, to quadruple-shape memory effect. More importantly, a highly matched actuating condition for shape recovery and healing was reached.

\section{EXPERIMENTAL SECTION}

\section{Regents and materials}

PTMEG (AR grade, $M_{\mathrm{n}}=2,000 \mathrm{~g} \mathrm{~mol}^{-1}$ ) was purchased from Sigma-Aldrich (USA). IPDI (98\%), 2,2-hydroxy ethyl disulfide (HEDS), triethanolamine (TEA, >98\%) were purchased from Alfa Aesar (USA). Dibutyltin dilaurate (DBTDL, 95\%) was purchased from Aladdin (Shanghai, China). N,N-Dimethylformamide (DMF, 99.9\%) was provided by Innochem (Beijing, China). Other reagents and solvents of A. R. grade were from Kelong Reagent Corp (Chengdu, China). All the reagents and solvents were dried before use.

\section{Preparation of PEUR-SS ${ }_{x}$-Ls and PEUR-SS $S_{x}$-Ns}

A series of PEUR-SS ${ }_{x}$-Ns with different disulfide bond contents $(x \%)$ and cross-linking degree were prepared as Scheme 1, the feed-ratios are listed in Table 1. Taking PEUR-SS ${ }_{12 \%}-\mathrm{N}_{3}$ as an example, first, PTMEG (1.6 g) was charged into a round flask and dried at $90^{\circ} \mathrm{C}$ under vacuum for $4 \mathrm{~h}$. Then, the temperature was reduced to $60^{\circ} \mathrm{C}$, and HEDS $(0.37 \mathrm{~g})$ and dry DMF $(20 \mathrm{~mL})$ were injected into the flask via a syringe under argon. With stirring for about two minutes, IPDI $(0.958 \mathrm{~mL})$ and DBTDL (5 drops) were added into the mixture to start the reaction. After that, two different routes were conducted parallel to each other. In route (i) for linear polymers (PEUR-SS ${ }_{x}$-Ls), to determine the structure of the intermediate linear prepolymer just before cross- 


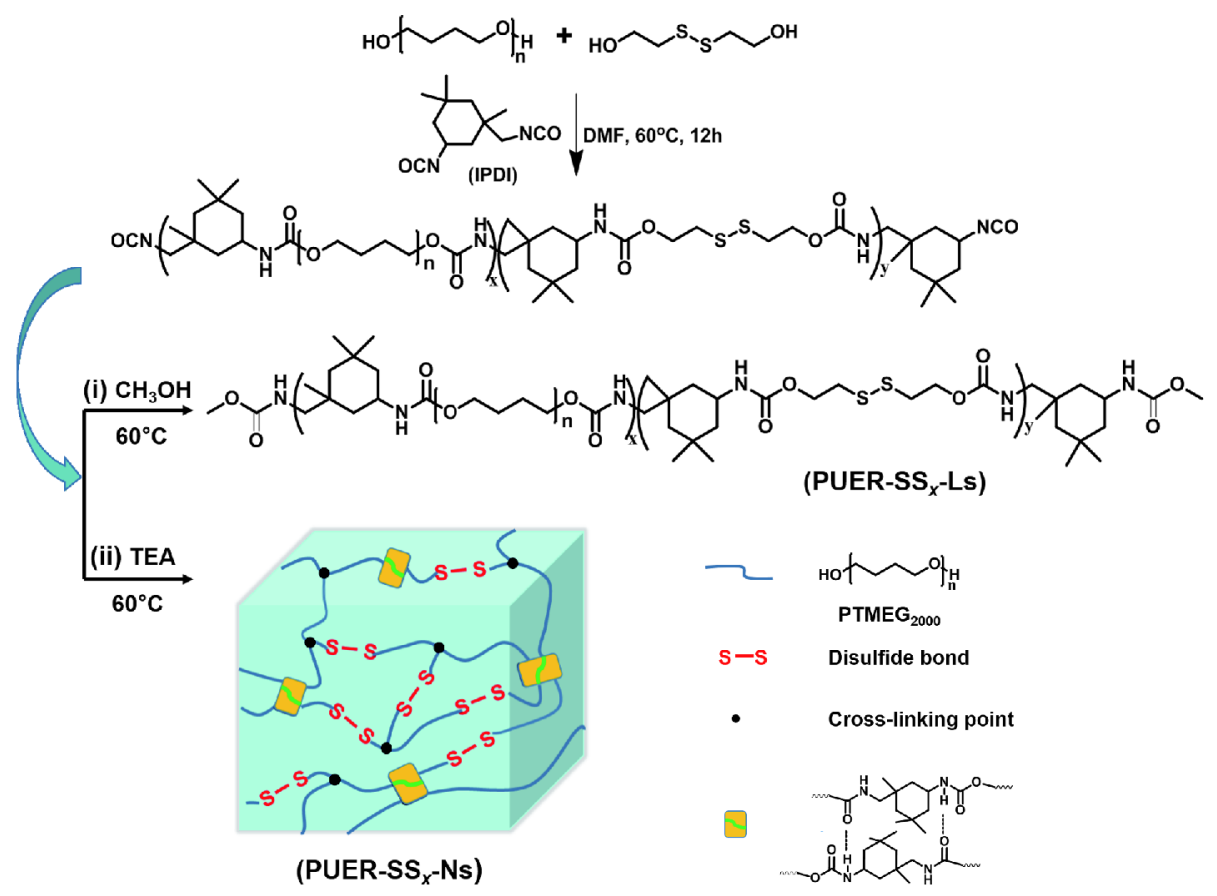

Scheme 1 The synthetic routes of the PEUR-SS Ps $_{x}$ and PEUR-SS - Ns.

Table 1 The feed ratio of the PEUR-SS - Ns and the swelling test results

\begin{tabular}{|c|c|c|c|c|c|c|c|}
\hline \multirow[b]{2}{*}{ Sample } & \multicolumn{5}{|c|}{ Feed ratio } & \multirow[b]{2}{*}{$G \%$} & \multirow[b]{2}{*}{$S \%$} \\
\hline & $\begin{array}{c}n\left(\mathrm{OH}_{\mathrm{diol}}\right): n\left(\mathrm{NCO}_{\mathrm{IPDI}}\right): \\
n\left(\mathrm{OH}_{\mathrm{TEA}}\right)\end{array}$ & $\begin{array}{l}\text { PTMEG } \\
(\mathrm{wt} \%)\end{array}$ & $\begin{array}{l}\text { HEDS } \\
(w t \%)\end{array}$ & $\begin{array}{l}\text { IPDI } \\
(w t \%)\end{array}$ & $\begin{array}{c}\text { TEA } \\
(w t \%)\end{array}$ & & \\
\hline PEUR-SS ${ }_{5 \%}-\mathrm{N}_{1}$ & $3: 4.2: 1.68$ & 69.0 & 5.3 & 21.9 & 3.7 & $14.0 \pm 0.7$ & $\mathrm{n} / \mathrm{a}$ \\
\hline PEUR-SS ${ }_{9 \%}-\mathrm{N}_{2}$ & $3: 4.2: 1.68$ & 58.4 & 9.0 & 27.8 & 4.8 & $12.3 \pm 1.7$ & $\mathrm{n} / \mathrm{a}$ \\
\hline PEUR-SS ${ }_{12 \%}-\mathrm{N}_{3}$ & $3: 4.2: 1.68$ & 50.6 & 11.7 & 32.1 & 5.6 & $13.2 \pm 1.2$ & $\mathrm{n} / \mathrm{a}$ \\
\hline PEUR-SS ${ }_{12 \%}-\mathrm{N}_{4}$ & $3: 4.2: 1.44$ & 51.0 & 11.8 & 32.3 & 4.9 & $49.1 \pm 1.7$ & $9,888 \pm 701$ \\
\hline PEUR-SS ${ }_{12 \%}-\mathrm{N}_{5}$ & $3: 4.2: 1.20$ & 51.4 & 11.9 & 32.6 & 4.1 & $75.0 \pm 0.9$ & $4,641 \pm 185$ \\
\hline PEUR-BD-N 6 & $3: 4.2: 1.68$ & 53.2 & 7.2 & 33.8 & 5.8 & $13.7 \pm 1.3$ & $\mathrm{n} / \mathrm{a}$ \\
\hline
\end{tabular}

Note: $\mathrm{n} / \mathrm{a}$ means that the cross-linking density is quite low so that no accurate data can be obtained.

linking, an excess of 15 times of anhydrous methanol was added to fully react for $6 \mathrm{~h}$, then poured into $150 \mathrm{~mL}$ water and precipitated, then centrifuged to obtain a linear polymer named PEUR-SS ${ }_{12 \%}-\mathrm{L}_{3}$. In route (ii) for target networks (PEUR-SS ${ }_{x}-\mathrm{Ns}$ ), after $12 \mathrm{~h}$ chain-extending reaction with presence of IPDI, TEA $(0.16 \mathrm{~mL})$ and DBTDL ( 5 drops) were added into the solution. After a period of pre-reaction, the solution was injected into a horizontal Teflon dish in a glass autoclave under the protection of an argon stream for further cross-linking and solvent evaporation at $45^{\circ} \mathrm{C}$ for two days. Then, the network was diverted into a drying oven at $45^{\circ} \mathrm{C}$ for one day and under vacuum for several days until a constant weight. A control sample PEUR-BD- $\mathrm{N}_{6}$ was also prepared, which had the same feed ratio of PUER-SS $12 \%-\mathrm{N}_{3}$ except the absence of disulfide bond.

\section{Characterization and measurements}

\section{Nuclear magnetic resonance}

${ }^{1} \mathrm{H}$-NMR spectra were recorded by using a Bruker AV400 spectrometers (Bruker, Germany) at $400 \mathrm{MHz}$ with deuterated chloroform $\left(\mathrm{CDCl}_{3}\right)$ as the solvent and tetramethyl silane as an internal reference at room temperature. 


\section{Gel permeation chromatography}

The molecular weight $\left(M_{\mathrm{w}}, M_{\mathrm{n}}\right.$ and polydispersity index $\left.M_{\mathrm{w}} / M_{\mathrm{n}}\right)$ of the PEUR-SS ${ }_{x}$-Ls was obtained by gel permeation chromatography (GPC) on a Waters instrument equipped with a model 1515 pump, 2414 refractive index detector, using polystyrene standards to construct the calibration curves. Tetrahydrofuran was used as eluent solvent at a flowing rate of $1 \mathrm{~mL} \mathrm{~min}^{-1}$ at $30^{\circ} \mathrm{C}$.

\section{Fourier transform infrared spectroscopy}

FT-IR was obtained by using a Nicolet MX-1IR spectrometer over the range of $500-4,000 \mathrm{~cm}^{-1}$ with a $2 \mathrm{~cm}^{-1}$ resolution. Solution-cast on a pure $\mathrm{KBr}$ substrate was used to the samples

\section{Raman spectroscopy}

Raman spectroscopy analysis was performed using a LabRAM HR800 Raman spectrometer (SPEX Co., USA) with a laser excitation wavelength of $785 \mathrm{~nm}$ on the range of $400-1,600 \mathrm{~cm}^{-1}$.

The swelling ratio and gel content of the PEUR-SS ${ }_{x}-N s$ The samples were cut into small slices, swelled, and extracted by chloroform for $24 \mathrm{~h}$. The masses of the original sample $\left(m_{0}\right)$, the swelled extracted sample $\left(m_{\mathrm{s}}\right)$ and the dried extracted sample $\left(m_{\mathrm{d}}\right)$ were recorded. The gel content $(G(\%))$ and the degree of swelling $(S(\%))$ were calculated using the following equations:

$$
\begin{aligned}
& G(\%)=\frac{m_{\mathrm{d}}}{m_{0}} \times 100 \%, \\
& S(\%)=\frac{m_{\mathrm{s}}}{m_{\mathrm{d}}} \times 100 \% .
\end{aligned}
$$

All of these data were measured three times and averaged.

\section{Differential scanning calorimetry}

Thermal properties of the polymers were acquired by differential scanning calorimetry (DSC) with a TA Instrument DSC Q200 (TA, USA) under a steady flow of ultrahigh purity nitrogen. Samples were heated to $70^{\circ} \mathrm{C}$ quickly, maintained for $3 \mathrm{~min}$ to eliminate the thermal history, and then cooled down to $-55^{\circ} \mathrm{C}$ at $5^{\circ} \mathrm{C} \mathrm{min}^{-1}$. Subsequently, the samples were heated again to $70^{\circ} \mathrm{C}$ at the same rate.

\section{Dynamic mechanical analysis}

The thermomechanical properties of the samples were evaluated by the dynamic mechanical analysis (DMA) Q800 instrument (TA, USA) with a heating rate of $3^{\circ} \mathrm{C} \mathrm{min}{ }^{-1}$ and a frequency of $1 \mathrm{~Hz}$ from -70 to $120^{\circ} \mathrm{C}$. The storage modulus $\left(E^{\prime}\right)$ and loss factor $(\tan \delta)$ were obtained.

\section{Self-healing effect}

The self-healing effect was investigated both qualitatively and quantitatively. The qualitative research mainly relied on the optical microscopy images which were recorded using an optical microscope (NIKON ECLIPSE LV100 POL, Japan) equipped with a digital camera. Images of cracks on sample surface before and after healing were obtained.

The quantitative analysis was performed by tensile tests at room temperature $\left(25^{\circ} \mathrm{C}\right)$ on a commercial tensile tester (INSTRON 3366, USA) at a crosshead speed of $50 \mathrm{~mm} \mathrm{~min}^{-1}$. The dumbbell-shaped film specimens were employed for testing, with $0.5 \mathrm{~mm}$ thickness, $4 \mathrm{~mm}$ width, and $20 \mathrm{~mm}$ length between the two pneumatic grips, respectively. The specific process of self-healing behavior was as follows: first, the specimen was damaged with a razor blade (the depth of incision was $95 \%$ of the sample thickness) and then the fractured surfaces were brought together, pressed for half a minute to allow full contact, followed by healing in the drying oven at $55^{\circ} \mathrm{C}$ for $12 \mathrm{~h}$. At least three samples were tested per network to get averaged results in each group.

The healing efficiency $(\eta)$ was evaluated by Equation (3). Here, the tensile strength of the original samples is expressed as $\sigma_{0}$, and the tensile strength of the healed strips is represented as $\sigma_{\mathrm{h}}$.

$$
\eta(\%)=\frac{\sigma_{\mathrm{h}}}{\sigma_{0}} \times 100 \% .
$$

\section{Shape-memory effect}

All quantitative shape-memory properties include dual-, triple-, and quadruple-shape memory effects were explored by using a DMA Q800 (TA Instruments, USA) with the controlled force mode. The detailed procedures and evaluation formulas were displayed in the Supplementary information (Methods S1).

\section{RESULTS AND DISCUSSION}

\section{Preparation of PEUR-SS ${ }_{x}$-Ls and PEUR-SS $x$-Ns}

The content of the dynamic bond as well as the mobility of the chain segment in the networks are key to determine the healing effect, while the architecture of network together with its thermal transition dominates the shapememory effect. Taking account of these factors, therefore, 
a
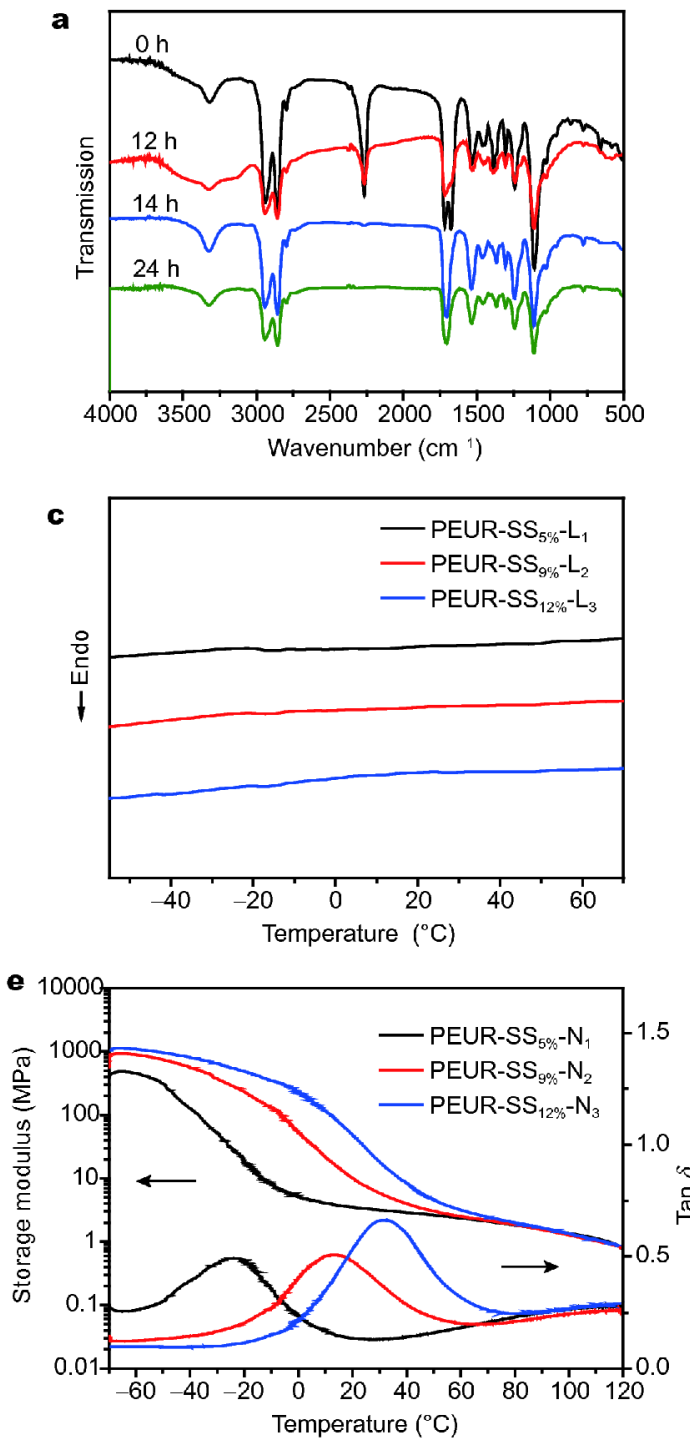
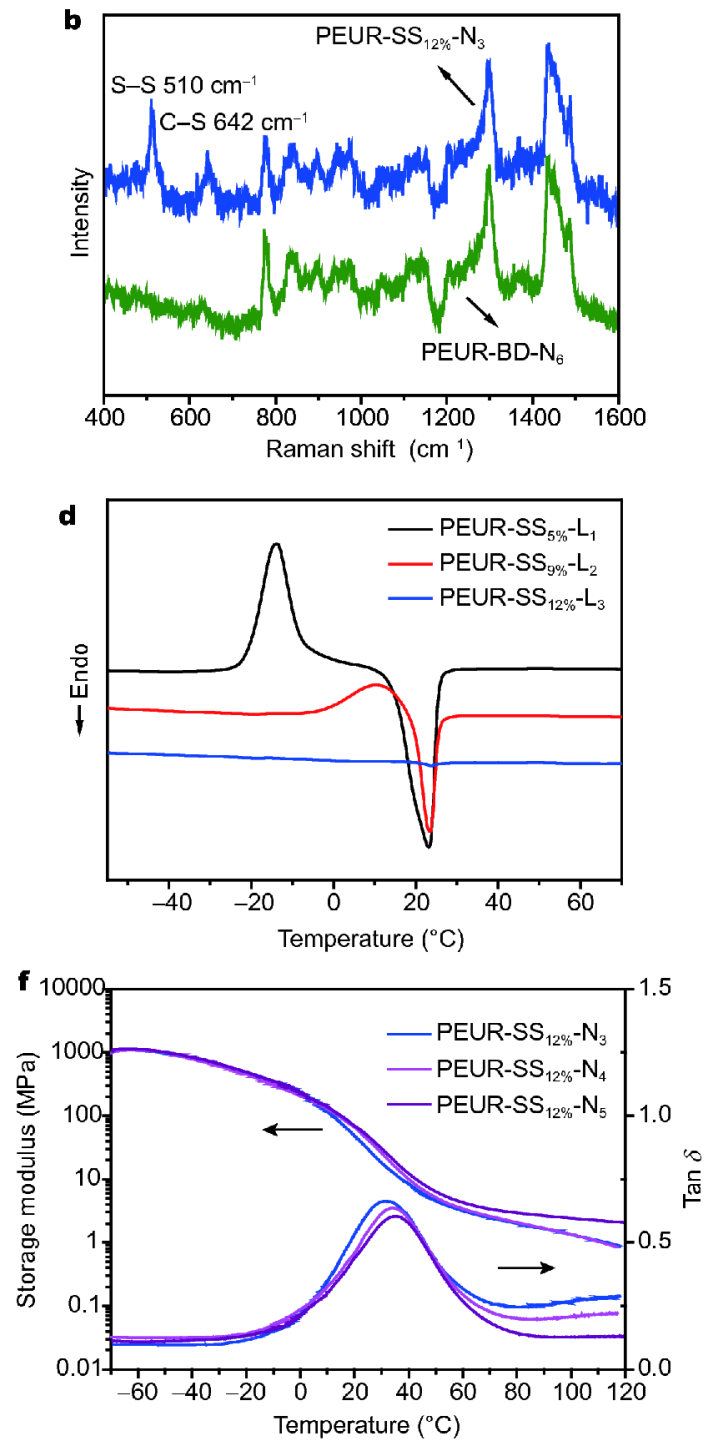

Figure 1 (a) FT-IR spectra of PEUR-SS ${ }_{12 \%}-\mathrm{N}_{3}$ obtained at 0, 12, 14 and $24 \mathrm{~h}$; (b) Raman spectra of PEUR-SS ${ }_{12 \%}-\mathrm{N}_{3}$ and PEUR-BD-N ; $_{6}$ (c) DSC cooling

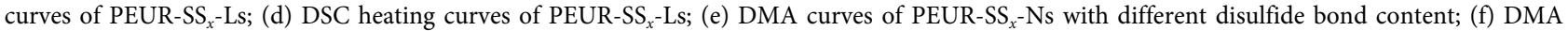
curves of PEUR-SS PNs $^{-N i t h ~ d i f f e r e n t ~ c r o s s-l i n k i n g ~ d e g r e e . ~}$

we prepared a series of PEUR-SS ${ }_{x}$-Ns by varying the disulfide bond and the cross-linking density.

The preparation strategy of PEUR-SS ${ }_{x}-\mathrm{Ns}$ is displayed schematically in Scheme 1. In order to fully understand the architecture of the network, the corresponding linear prepolymers PEUR-SS ${ }_{x}$-Ls before cross-linking were also prepared and characterized by the ${ }^{1} \mathrm{H}-\mathrm{NMR}$ and GPC (all details are listed in Fig. S1 and Table S1). Concerning the networks fabrication, we used FT-IR (Fig. 1a) to monitor the whole process by observing the strength of $-\mathrm{NCO}$ peak to determine the degree of reaction. The $-\mathrm{NCO}$ group showed a strong peak at around $2,266 \mathrm{~cm}^{-1}$ at the beginning of the reaction. After $12 \mathrm{~h}$ chain-extending reaction, the peak intensity decreased but was still visible, which indicated that the linear prepolymer was terminated by -NCO group. When the cross-linker TEA was added, the peak intensity decreased obviously, which meant that the reminding -NCO group was consumed by TEA. At last, the -NCO peak disappeared in the final casting film, indicating the reaction was complete. The swelling test was performed to assess the cross-linking degree, and the results are listed in Table 1 . The crosslinking degree was tuned by the amount of TEA. The network $\mathrm{N}_{1}, \mathrm{~N}_{2}$ and $\mathrm{N}_{3}$ have different contents of disulfide 
Table 2 Mechanical properties of PEUR-SS ${ }_{x}-\mathrm{Ns}$ at original state and after healed: tensile strength $(\sigma)$, ultimate elongation $(\varepsilon)$, and healing efficiencies $(\eta)$

\begin{tabular}{|c|c|c|c|c|c|}
\hline \multirow{2}{*}{ Sample } & \multicolumn{2}{|l|}{ Original } & \multicolumn{2}{|c|}{ Healed } & \multirow{2}{*}{$\eta(\%)$} \\
\hline & $\sigma(\mathrm{MPa})$ & $\varepsilon(\%)$ & $\sigma(\mathrm{MPa})$ & $\varepsilon(\%)$ & \\
\hline PEUR-SS ${ }_{5 \%}-\mathrm{N}_{1}$ & $3.02 \pm 0.25$ & $1864 \pm 98$ & $1.99 \pm 0.20$ & $1455 \pm 133$ & 66 \\
\hline PEUR-SS ${ }_{9 \%}-\mathrm{N}_{2}$ & $4.83 \pm 0.05$ & $1671 \pm 40$ & $3.98 \pm 0.09$ & $1435 \pm 26$ & 82 \\
\hline PEUR-SS ${ }_{12 \%}-\mathrm{N}_{3}$ & $6.09 \pm 0.29$ & $1187 \pm 58$ & $5.75 \pm 0.17$ & $1114 \pm 63$ & 94 \\
\hline PEUR-SS ${ }_{12 \%}-\mathrm{N}_{4}$ & $8.32 \pm 0.41$ & $1145 \pm 20$ & $6.12 \pm 0.30$ & $1074 \pm 85$ & 74 \\
\hline PEUR-SS ${ }_{12 \%}-\mathrm{N}_{5}$ & $15.5 \pm 0.72$ & $960 \pm 17$ & - & - & - \\
\hline PEUR-BD-N 6 & $7.68 \pm 0.18$ & $1130 \pm 74$ & $3.11 \pm 0.10$ & $707 \pm 11$ & 40 \\
\hline
\end{tabular}

bonds but similar cross-linking degree with a low gel content ranging from $10 \%$ to $15 \%$, since an excessive TEA was added. Keeping the same content of disulfide bonds with $\mathrm{N}_{3}$, network $\mathrm{N}_{4}$ and $\mathrm{N}_{5}$ were prepared by decreasing the amount of TEA till an equivalent dose. Thus, $\mathrm{N}_{5}$ showed a highest cross-linking degree with gel content of $75 \%$.

The incorporation of disulfide bonds in the networks was confirmed by Raman spectra (Fig. 1b). For a typical sample PEUR-SS ${ }_{12 \%}-\mathrm{N}_{3}$, the $v(\mathrm{~S}-\mathrm{S})$ band at $510 \mathrm{~cm}^{-1}$ and $v(\mathrm{C}-\mathrm{S})$ band at $642 \mathrm{~cm}^{-1}$ can be observed, while no relevant peaks are found in the control PEUR-BD-N 6 without disulfide bonds. The Raman spectra of the other samples are presented in Fig. S2.

\section{Thermal behavior of PEUR-SS PLs $_{x}$ and PEUR-SS Ps $_{x}$}

DSC was employed to reveal the thermal behavior of PEUR before and after cross-linking. The curves of PEUR-SS ${ }_{x}$-Ls and PEUR-SS - Ns are illustrated in Fig. 1c, $\mathrm{d}$ and Fig. S3a, b, respectively, and all relevant data are listed in Table S2. For the linear samples, a visible effect of disulfide bond content on the crystalline behavior of PTMEG segment was found. It is easy to understand that the incorporation of disulfide bonds disturbs the regularity of PTMEG chains. In detail, an evident crystallization and melting peak are observed in PEUR-SS ${ }_{5 \%}-\mathrm{L}_{1}$. However, with the increase of disulfide content, the crystallization of the samples is depressed severely, so that only a very weak melting peak is detected in PEUR-SS ${ }_{12 \%}$ $\mathrm{L}_{3}$. After cross-linking (Fig. S3), the crystallization of the PTMEG segment has been restricted further and no peak is observed for all networks during the whole scanning process. That means PTMEG segment is in an amorphous state, which would benefit the mobility of chain segment.

Dynamic mechanical properties of PEUR-SS -Ns. $^{-}$ DMA was employed to analyze the thermomechanical properties of the materials. Fig. 1e illustrates the storage modulus $\left(E^{\prime}\right)$ and loss factor $(\tan \delta)$ curves of the samples with low cross-linking degree but different disulfide bond contents. At the beginning, the sample with higher disulfide bond content exhibits higher $E$, because more urethane bonds are incorporated. With increasing temperature, it slightly declines at first and then an evidently drop is observed when the temperature crosses $T_{\mathrm{g}}$. Finally, a plateau appears in the curves, which indicates the formation of network. For the $\tan \delta$ curves, one can find that $T_{\mathrm{g}}$ increases with the disulfide bond content. More importantly, all samples show a very wide range of $T_{\mathrm{g}}$ transition, which enable the material with a multi-shape memory effect. Fig. If reflects the $E^{\prime}$ and $\tan \delta$ of the samples with same disulfide bond content but different cross-linking degree. Compared with disulfide bond content, the cross-linking degree of networks only has slight influence on $E^{\prime}$ and $T_{\mathrm{g}}$.

\section{Mechanical properties and self-healing behavior}

Disulfide exchange has attracted significant attention because it can be activated at relatively moderate temperatures. Herein, we introduced the disulfide bond into the PEUR networks to seek the self-healing capacity in a mild condition. In fact, the incorporation of dynamic interaction will usually sacrifice the mechanical performance, and how to produce the self-healing material with desirable mechanical performance is crucial. So, we firstly investigated the effect of the disulfide bond content and the cross-link density on the tensile properties of the pristine networks, and then the results of the healed samples were also recorded to evaluate the self-healing efficiency (see details in Table 2). The detailed process of self-healing behavior was introduced in EXPERIMENT SECTION and the efficiency was calculated by Equation (3).

For the pristine strips with similar cross-linking degree, 

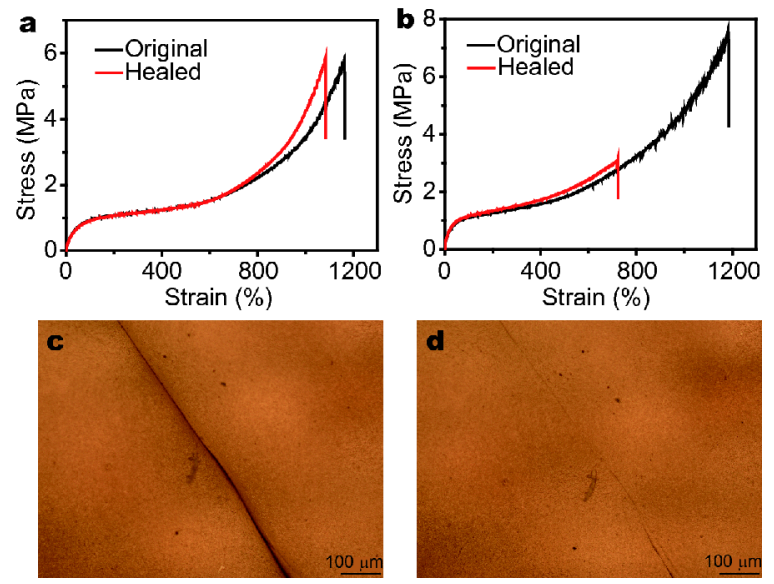

Figure 2 The self-healing effect of PEUR-SS ${ }_{x}$-Ns: (a) stress-strain curves of self-healing tests for the PEUR-SS $12 \%-\mathrm{N}_{3}$; (b) stress-strain curves of PEUR-BD- $\mathrm{N}_{6}$; (c) optical micrograph of the PEUR-SS ${ }_{12 \%}-\mathrm{N}_{3}$ before healing treatment; (d) optical micrograph of the PEUR-SS $12 \%-\mathrm{N}_{3}$ healed at $55^{\circ} \mathrm{C}$ for $30 \mathrm{~min}$.

$\sigma$ increases with increasing content of the disulfide bond, while $\varepsilon$ has the opposite variation tendency. It may be ascribed to the increase of the hard segment at the same time. A typical sample PEUR-SS $12 \%-\mathrm{N}_{3}$ containing $12 \%$ disulfide bond exhibits $\sigma$ of $6.09 \mathrm{MPa}$ and $\varepsilon$ more than $1100 \%$. For the samples with same disulfide bond, $\sigma$ is also enhanced with an increase in the degree of crosslinking, while $\varepsilon$ has the opposite trend. PEUR-SS $12 \%-\mathrm{N}_{5}$ with the highest degree of cross-linking exhibits $\sigma$ of 15.5 MPa and $\varepsilon$ about $960 \%$.

Self-healing test was also conducted for all networks, the typical engineering stress-strain curve of PEUR-SS ${ }_{12 \%}$ $\mathrm{N}_{3}$ is shown in Fig. 2a, and the others are listed in Fig. S4a-d. All the results are summarized in Table 2. It can be clearly seen that the healing efficiency of the material increases from $66 \%$ to $94 \%$ with increasing disulfide bond content from $5 \%$ to $12 \%$, respectively. However, the healing ability deteriorates sharply with the increase of cross-linking degree, due to the serious restriction on the mobility of the chain segment. Especially for the PEUR$\mathrm{SS}_{12 \%}-\mathrm{N}_{5}$ with highest cross-linking degree, the material almost loses the healing capacity. Taking PEUR-SS ${ }_{12 \%}-\mathrm{N}_{3}$ as an example which owns the best self-healing performance, the repeat-healing test was conducted. The sample was cut and self-healed at $55^{\circ} \mathrm{C}$ for $12 \mathrm{~h}$ and this process was repeated one or two times in the same location. The stress-strain curves are shown in Fig. S4e, and the healing efficiencies were calculated around $90 \%$. It reveals that the material exhibits good repeated healing performance.

In order to demonstrate that the healing effect is dominated by the disulfide exchange in the matrix, we prepared a control sample which had the same composition with PEUR-SS ${ }_{12 \%}-\mathrm{N}_{3}$ except for substituting HEDS with $\mathrm{BD}$, named PEUR-BD- $\mathrm{N}_{6}$ (the dynamic mechanical properties are listed in Fig. S5). The stress-strain curves of tensile tests for the original sample and healed one are displayed in Fig. 2b. Without disulfide bonds, the efficiency of the sample repair is calculated as about $40 \%$, which may be attributed to the hydrogen bonding between urethane groups. The self-healing effect of the PEUR-SS ${ }_{x}$-Ns was also recorded by an optical microscope. Here, only a typical sample PEUR-SS $12 \%-\mathrm{N}_{3}$ was chosen to display the effect macroscopically. First, a crack was scraped by a fresh razor blade (Fig. 2c), and then the sample was heated to $55^{\circ} \mathrm{C}$. Clearly, the scratch almost disappeared in about $30 \mathrm{~min}$ (Fig. 2d).

\section{Versatile shape memory effects}

The shape-memory effects of polyurethane materials have been extensively studied. According to DMA analyses, the PEUR-SS ${ }_{x}$-Ns displays a broad $T_{\mathrm{g}}$ transition, which not only makes it have dual-shape memory effect, but also a good candidate as a multi-shape memory material. Considering that the practicality and reasonability of the temperature range, we choose PEUR-SS ${ }_{12 \%}-\mathrm{Ns}$ series for shape-memory effect evaluation, whose $T_{\mathrm{g}}$ are slightly higher than that of other samples. Herein, the glass transition of network acts as the molecular switch, the cross-linking serves as the netpoint. Fig. 3 illustrates the dual- , triple- and quadruple-shape memory effect of a typical sample PEUR-SS ${ }_{12 \%}-\mathrm{N}_{4}$, and the cyclic thermal mechanical curves of the others are displayed in Figs S6 and S7.

On the basis of the previous analyses of self-healing, it can be seen that healing efficiency was raised with the increase of disulfide bond content, but gradually decreased with the increase of cross-linking degree. Herein, we try to develop a material with both excellent shape memory and self-healing property, so we discuss shapememory effect from low cross-linking to high crosslinking. The quantifications of dual-shape memory effect for PEUR-SS $12 \%$-Ns with different cross-linking were calculated with Equation (S1) and (S2), and the results are summarized in Table 3. Apparently, all three networks have excellent shape fixing property with $R_{\mathrm{f}}$ around $99.3 \%-99.9 \%$. However, the recovery property is found highly dependent on the cross-linking density, i.e., the $R_{\mathrm{r}}$ is gradually increasing from $87 \%$ to $97.4 \%$. PEUR-SS $12 \%$ $\mathrm{N}_{5}$ possesses the best dual-shape memory effect since it has the strongest netpoint. Contrarily, PEUR-SS $12 \%-\mathrm{N}_{3}$ shows unsatisfied dual-shape memory effect (Fig. S6), so 

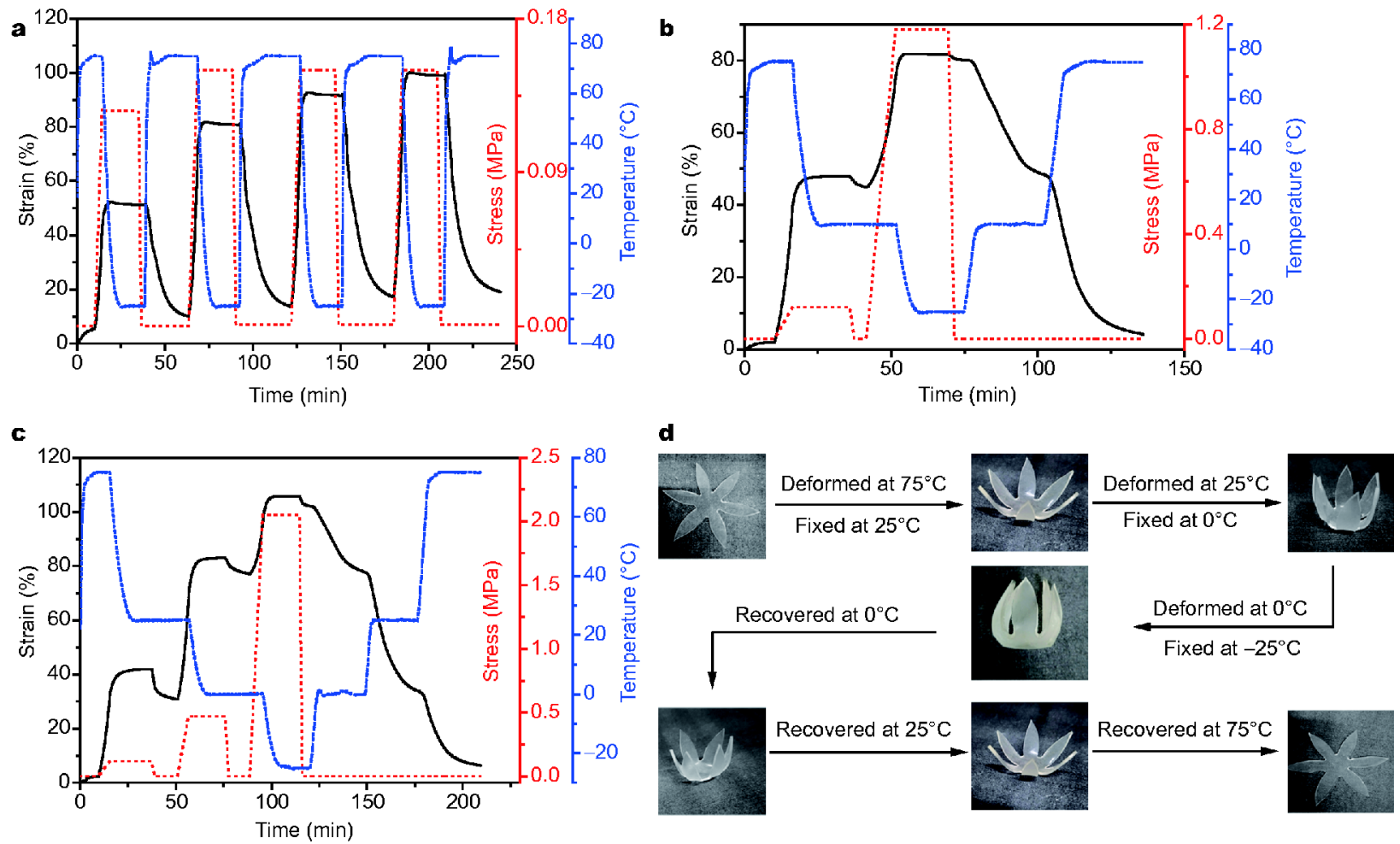

Figure 3 Versatile shape-memory effect of PEUR-SS ${ }_{12 \%}-\mathrm{N}_{4}$ recorded by DMA and digital camera: (a) dual-shape memory effect with $T_{\text {low }}=-25^{\circ} \mathrm{C}$, $T_{\text {high }}=75^{\circ} \mathrm{C}$; (b) triple-shape memory effect with $T_{\text {low }}=-25^{\circ} \mathrm{C}, T_{\text {mid }}=10^{\circ} \mathrm{C}, T_{\text {high }}=75^{\circ} \mathrm{C}$; (c) quadruple-shape memory effect with $T_{\text {low }}=-25^{\circ} \mathrm{C}, T_{\text {mid } 1}=0^{\circ} \mathrm{C}$, $T_{\text {mid } 2}=25^{\circ} \mathrm{C}, T_{\text {high }}=75^{\circ} \mathrm{C}$; (d) digital images of quadruple-shape memory effect.

Table 3 The quantitative shape memory effect of the PEUR-SS ${ }_{x}$-Ns

\begin{tabular}{|c|c|c|c|c|c|c|}
\hline \multirow{2}{*}{ Sample } & \multicolumn{2}{|c|}{ Dual- } & \multicolumn{2}{|c|}{ Triple- } & \multicolumn{2}{|c|}{ Quadruple- } \\
\hline & $R_{\mathrm{r}} \%$ & $R_{\mathrm{f}} \%$ & $R_{\mathrm{f}} \%^{\mathrm{a}}$ & $R_{\mathrm{r}} \%^{\mathrm{a}}$ & $R_{\mathrm{f}} \%^{\mathrm{b}}$ & $R_{\mathrm{r}} \%^{\mathrm{b}}$ \\
\hline PEUR-SS ${ }_{12 \%}-\mathrm{N}_{3}$ & $99.9 \pm 0.05$ & $87 \pm 2.47$ & - & - & - & - \\
\hline PEUR-SS ${ }_{12 \%}-\mathrm{N}_{4}$ & $99.7 \pm 0$ & $96 \pm 1.21$ & $93.7,96.0$ & $90.8,97.0$ & $71.9,88.6,86.8$ & $98.2,94.6,95.7$ \\
\hline PEUR-SS $_{12 \%}-\mathrm{N}_{5}$ & $99.3 \pm 0$ & $97.4 \pm 1.14$ & $76.6,95.8$ & $99.4,98.5$ & $45.6,72.8,87.9$ & $100,96.8,96.7$ \\
\hline
\end{tabular}

a) $R_{\mathrm{f}} \%$ and $R_{\mathrm{r}} \%$ during the two steps in triple-shape memory effect are list in sequence of proceeding; b) $R_{\mathrm{f}} \%$ and $R_{\mathrm{r}} \%$ during the three steps in quadruple-shape memory effect are listed in sequence of proceeding.

it has not been addressed in the followed discussion.

The triple-shape memory effect of PEUR-SS ${ }_{12 \%}-\mathrm{N}_{4}$ is demonstrated in Fig. 3b. As mentioned above, the polyurethane has a broad glass transition from -25 to $75^{\circ} \mathrm{C}$, which makes it a potential candidate for triple-shape memory effect. Thus, $T_{\text {high }}=75^{\circ} \mathrm{C}, T_{\text {mid }}=10^{\circ} \mathrm{C}$ and $T_{\text {low }}=$ $-25^{\circ} \mathrm{C}$ were set in the triple-shape memory effect test, and the $R_{\mathrm{f}}$ and $R_{\mathrm{r}}$ were calculated according to the Equation (S3) and (S4) (see detail in Supplementary information, Method S1). When the cross-linking degree increased, the recovery properties were improved. In detail, for recovery property, $R_{\mathrm{r}}\left(\mathrm{S}_{2}-\mathrm{S}_{1}\right)$ increases from $90.8 \%$ to $99.4 \%, R_{\mathrm{r}}\left(\mathrm{S}_{2}\right.$ $-S_{0}$ ) slightly shifts from $97 \%$ to $98.5 \%$. For the fixing property, the $R_{\mathrm{f}}\left(\mathrm{S}_{1}\right)$ reduces from $93.7 \%$ to $76.6 \%$, though $R_{\mathrm{f}}\left(\mathrm{S}_{2}\right)$ keeps high level around $96 \%$. It makes sense that more shapes need to fix based on a single broad thermal transition, and the fixing property for each shape will decline in a certain degree, and worsen with the increase of the cross-linking degree. To pursue more capability of multiple shape, quadruple-shape memory effect test with a temperature interval at least $25^{\circ} \mathrm{C}\left(T_{\text {low }}=-25^{\circ} \mathrm{C}, T_{\text {midl }}=\right.$ $0^{\circ} \mathrm{C}, T_{\text {mid } 2}=25^{\circ} \mathrm{C}, T_{\text {high }}=75^{\circ} \mathrm{C}$ ) was performed (Fig. $3 \mathrm{c}$ ). The rule is found in accordance with that of triple-shape memory effect. The $R_{\mathrm{f}}$ and $R_{\mathrm{r}}$ about each programming and recovery step of the quadruple-shape memory effect in the gradual deformation and recovery process were 

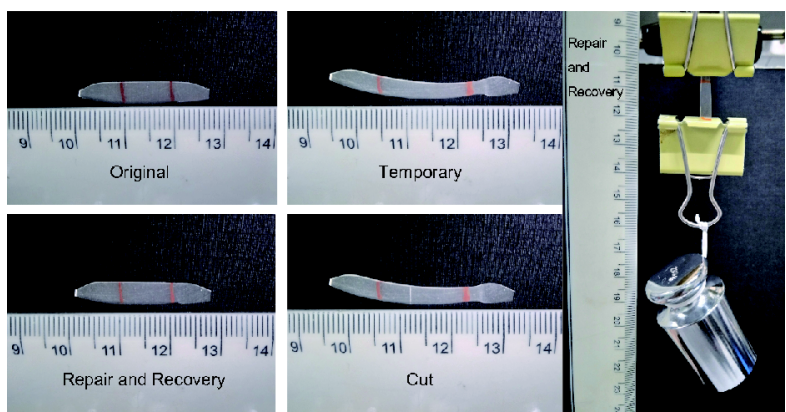

Figure 4 The model of synchronous repair and recovery based on PEUR-SS $12 \%-\mathrm{N}_{4}$.

calculated with Equation (S3) and (S4), and the results are listed in Table 3. Of course, the fixing properties of PEUR-SS ${ }_{12 \%}-\mathrm{N}_{4}$ are better than that of the PEUR-SS ${ }_{12 \%}$ $\mathrm{N}_{5}$. A flower model based on the former sample was employed to demonstrate the quadruple-shape memory effect by recording the closing and blooming process in steps with a digital camera (Fig. 3d). It is worth mentioning that two networks display very good recovery properties in each stage with the $R_{\mathrm{r}}$ values beyond $94 \%$. So we conducted multi-stage recovery test of the PEUR$\mathrm{SS}_{12 \%}-\mathrm{N}_{5}$ (see thermal mechanical curve in Fig. S7d), and a desirable performance with $R_{\mathrm{f}}$ of $99.1 \%$ and $R_{\mathrm{r}}$ of $96.9 \%$ is achieved, which means that the material can also present five different shapes just after one step programming.

\section{Simultaneous recovery and self-healing behavior}

After taking a full view of the self-healing and shapememory behaviors of these PEUR-SS ${ }_{x}$-Ns, we found that the trigger temperature for shape-memory effect was also in a suitable temperature range for healing. On one hand, the chain mobility of switch domain is activated when the temperature is higher than $T_{\text {trans }}$, which is a great benefit for the self-healing; on the other hand, this temperature is also allowing the bond exchange of disulfide bonds. So we put forward a new strategy to realize simultaneous recovery and self-healing in current materials. Herein, PEUR-SS ${ }_{12 \%}-\mathrm{N}_{4}$ was chosen for the test considering its own good balance on shape-memory effect and selfhealing effect. As recorded in Fig. 4, the sample in original shape was firstly programed to a temporary shape, and then a scratch was created on it with a knife. When recovered at $75^{\circ} \mathrm{C}$, the scratch disappeared, and meanwhile a recovery and repair was achieved in about $40 \mathrm{~min}$. The recovered sample can fully withstand the $200 \mathrm{~g}$ weight. Moreover, the shape-memory properties have been maintained very well after healing. It was confirmed by cyclic thermal mechanical test of the repaired and recovered sample (Fig. S8) with dual-shape mode, which indicated a good shape-memory performance with $R_{\mathrm{f}}$ of $99.8 \%$ and $R_{\mathrm{r}}$ of $95.8 \%$. This material with the capability of simultaneous recovery and self-healing has great potential in the application of sensors.

\section{CONCLUSIONS}

In conclusion, we prepared a series of polyurethane networks with different content of disulfide bonds and crosslinking degree via reaction of PTMEG, IPDI, functional monomer HEDS and cross-linker TEA by a one-pot method. The analysis of thermal behavior by DSC indicated that the PTMEG segment was in amorphous state after cross-linking, and all networks own a broad $T_{\mathrm{g}}$ transition. With increasing content of disulfide bonds and cross-linking degree, the tensile strength of the sample was enhanced, with PEUR-SS ${ }_{12 \%}-\mathrm{N}_{5}$ exhibiting the highest value of $15.5 \mathrm{MPa}$. According to the healing test, the sample PEUR-SS ${ }_{12 \%}-\mathrm{N}_{3}$ with the highest disulfide bond content but low cross-linking degree presented the best healing efficiency of $94 \%$ at $55^{\circ} \mathrm{C}$ for $12 \mathrm{~h}$. For shapememory effect evaluation, the networks with relatively high degree of cross-linking present the dual-, triple- and quadruple shape memory effects. To realize the simultaneous recovery and self-healing in one programming cycle, PEUR-SS ${ }_{12 \%}-\mathrm{N}_{4}$ with the good balance of shapememory effect and self-healing effect was chosen to establish this model, and an expected result was achieved.

Received 5 May 2018; accepted 26 June 2018;

published online 26 July 2018

1 Lendlein A, Kelch S. Shape-memory polymers. Angew Chem Int Ed, 2002, 41: 2034-2057

2 Behl M, Lendlein A. Shape-memory polymers. Mater Today, 2007, 10: $20-28$

3 Lendlein A, Langer R. Biodegradable, elastic shape-memory polymers for potential biomedical applications. Science, 2002, 296 : 1673-1676

4 Huang WM, Song CL, Fu YQ, et al. Shaping tissue with shape memory materials. Adv Drug Deliver Rev, 2013, 65: 515-535

5 Pilate F, Toncheva A, Dubois P, et al. Shape-memory polymers for multiple applications in the materials world. Eur Polymer J, 2016, 80: 268-294

6 Sun L, Huang WM, Wang CC, et al. Polymeric shape memory materials and actuators. Liquid Crysts, 2013, 41: 277-289

7 Behl M, Razzaq MY, Lendlein A. Multifunctional shape-memory polymers. Adv Mater, 2010, 22: 3388-3410

8 Yang Y, Urban MW. Self-healing polymeric materials. Chem Soc Rev, 2013, 42: 7446-7467

9 Wool RP. Self-healing materials: a review. Soft Matter, 2008, 4: 400

10 Wu DY, Meure S, Solomon D. Self-healing polymeric materials: a review of recent developments. Prog Polymer Sci, 2008, 33: 479522 
11 Mauldin TC, Kessler MR. Self-healing polymers and composites. Int Mater Rev, 2013, 55: 317-346

12 Syrett JA, Becer CR, Haddleton DM. Self-healing and self-mendable polymers. Polym Chem, 2010, 1: 978-987

13 Jia R, Li L, Ai Y, et al. Self-healable wire-shaped supercapacitors with two twisted $\mathrm{NiCo}_{2} \mathrm{O}_{4}$ coated polyvinyl alcohol hydrogel fibers. Sci China Mater, 2018, 61: 254-262

14 Boyer C, Hoogenboom R. Multi-responsive polymers. Eur Polymer J, 2015, 69: 438-440

15 Xie T. Recent advances in polymer shape memory. Polymer, 2011, 52: 4985-5000

16 Zhan MQ, Yang KK, Wang YZ. Shape-memory poly(p-dioxanone)-poly(-caprolactone)/sepiolite nanocomposites with enhanced recovery stress. Chin Chem Lett, 2015, 26: 1221-1224

17 Miaudet P, Derré A, Maugey M, et al. Shape and temperature memory of nanocomposites with broadened glass transition. Science, 2007, 318: 1294-1296

18 Xie T. Tunable polymer multi-shape memory effect. Nature, 2010, 464: $267-270$

19 Luo Y, Guo Y, Gao X, et al. A general approach towards thermoplastic multishape-memory polymers via sequence structure design. Adv Mater, 2013, 25: 743-748

20 Wen Z, Zhang T, Hui Y, et al. Elaborate fabrication of well-defined side-chain liquid crystalline polyurethane networks with tripleshape memory capacity. J Mater Chem A, 2015, 3: 13435-13444

21 Cui J, del Campo A. Multivalent H-bonds for self-healing hydrogels. Chem Commun, 2012, 48: 9302-9304

22 Wei M, Zhan M, Yu D, et al. Novel poly(tetramethylene ether) glycol and poly( $\varepsilon$-caprolactone) based dynamic network via quadruple hydrogen bonding with triple-shape effect and selfhealing capacity. ACS Appl Mater Interfaces, 2015, 7: 2585-2596

23 Zhu D, Ye Q, Lu X, et al. Self-healing polymers with PEG oligomer side chains based on multiple $\mathrm{H}$-bonding and adhesion properties. Polym Chem, 2015, 6: 5086-5092

24 Hui Y, Wen ZB, Pilate F, et al. A facile strategy to fabricate highlystretchable self-healing poly(vinyl alcohol) hybrid hydrogels based on metal-ligand interactions and hydrogen bonding. Polym Chem, 2016, 7: 7269-7277

25 Burattini S, Colquhoun HM, Fox JD, et al. A self-repairing, supramolecular polymer system: healability as a consequence of donor-acceptor $\pi-\pi$ stacking interactions. Chem Commun, 2009, 319: 6717-6719

26 Zhong HY, Chen L, Ding XM, et al. Physio- and chemo-dual crosslinking toward thermoand photo-response of azobenzene-containing liquid crystalline polyester. Sci China Mater, 2018, 61: 1225-1236

27 Kakuta T, Takashima Y, Nakahata M, et al. Preorganized hydrogel: self-healing properties of supramolecular hydrogels formed by polymerization of host-guest-monomers that contain cyclodextrins and hydrophobic guest groups. Adv Mater, 2013, 25: 2849-2853

28 Zhang M, Xu D, Yan X, et al. Self-healing supramolecular gels formed by crown ether based host-guest interactions. Angew Chem Int Ed, 2012, 51: 7011-7015

29 Chen X, Dam MA, Ono K, et al. A thermally re-mendable crosslinked polymeric material. Science, 2002, 295: 1698-1702

30 Li QT, Jiang MJ, Wu G, et al. Photothermal conversion triggered precisely targeted healing of epoxy resin based on thermoreversible Diels-Alder network and amino-functionalized carbon nanotubes. ACS Appl Mater Interfaces, 2017, 9: 20797-20807

31 Zhang J, Niu Y, Huang C, et al. Self-healable and recyclable triple- shape PPDO-PTMEG co-network constructed through thermoreversible Diels-Alder reaction. Polym Chem, 2012, 3: 1390-1393

32 Canadell J, Goossens H, Klumperman B. Self-healing materials based on disulfide links. Macromolecules, 2011, 44: 2536-2541

33 Lafont U, van Zeijl H, van der Zwaag S. Influence of cross-linkers on the cohesive and adhesive self-healing ability of polysulfidebased thermosets. ACS Appl Mater Interfaces, 2012, 4: 6280-6288

34 Yang WJ, Tao X, Zhao T, et al. Antifouling and antibacterial hydrogel coatings with self-healing properties based on a dynamic disulfide exchange reaction. Polym Chem, 2015, 6: 7027-7035

35 An SY, Noh SM, Nam JH, et al. Dual sulfide-disulfide cross-linked networks with rapid and room temperature self-healability. Macromol Rapid Commun, 2015, 36: 1255-1260

$36 \mathrm{Xu} \mathrm{Y}$, Chen $\mathrm{D}$. A novel self-healing polyurethane based on disulfide bonds. Macromol Chem Phys, 2016, 217: 1191-1196

37 Kim SM, Jeon H, Shin SH, et al. Superior toughness and fast selfhealing at room temperature engineered by transparent elastomers. Adv Mater, 2018, 30: 1705145-1705152

38 Rekondo A, Martin R, Ruiz de Luzuriaga A, et al. Catalyst-free room-temperature self-healing elastomers based on aromatic disulfide metathesis. Mater Horiz, 2014, 1: 237-240

39 Deng G, Tang C, Li F, et al. Covalent cross-linked polymer gels with reversible sol-gel transition and self-healing properties. Macromolecules, 2010, 43: 1191-1194

40 Liu F, Li F, Deng G, et al. Rheological images of dynamic covalent polymer networks and mechanisms behind mechanical and selfhealing properties. Macromolecules, 2012, 45: 1636-1645

41 Roberts MC, Hanson MC, Massey AP, et al. Dynamically restructuring hydrogel networks formed with reversible covalent cross-links. Adv Mater, 2007, 19: 2503-2507

42 He L, Fullenkamp DE, Rivera JG, et al. $\mathrm{pH}$ responsive self-healing hydrogels formed by boronate-catechol complexation. Chem Commun, 2011, 47: 7497-7499

43 Zhang Y, Yang B, Zhang X, et al. A magnetic self-healing hydrogel. Chem Commun, 2012, 48: 9305-9307

44 Zhang Y, Tao L, Li S, et al. Synthesis of multiresponsive and dynamic chitosan-based hydrogels for controlled release of bioactive molecules. Biomacromolecules, 2011, 12: 2894-2901

45 Rodriguez ED, Ounaies Z, Luo XF, Mather PT. Shape memory miscible blends for thermal mending. Proc of SPIE, 2009, 7289: 728912

46 Luo X, Mather PT. Shape memory assisted self-healing coating. ACS Macro Lett, 2013, 2: 152-156

47 Rodriguez ED, Luo X, Mather PT. Linear/network poly( $\varepsilon$-caprolactone) blends exhibiting shape memory assisted self-healing (SMASH). ACS Appl Mater Interfaces, 2011, 3: 152-161

48 Du L, Xu ZY, Fan CJ, et al. A fascinating metallo-supramolecular polymer network with thermal/magnetic/light-responsive shapememory effects anchored by $\mathrm{Fe}_{3} \mathrm{O}_{4}$ nanoparticles. Macromolecules, 2018, 51: 705-715

Acknowledgements This work was supported financially by the National Natural Science Foundation of China (51773131 and 51721091), and the International S\&T Cooperation Project of Sichuan Province (2017HH0034).

Author contributions Deng XY performed the experiments; Deng XY and Yang KK analyzed the data and wrote the draft of manuscript; Yang $\mathrm{KK}$ and Wang $\mathrm{YZ}$ proposed the project and critical comments on the writing of the manuscript; Xie $\mathrm{H}$ and Fan $\mathrm{CJ}$ provided some additional 
suggestions on experiments; Du L and Cheng CY checked and approved the manuscript. All authors discussed the results.

Conflict of interest The authors declare that they have no conflict of interest.

Supplementary information Supplementary materials are available in the online version of the paper, including program for shape-memory effect, ${ }^{1} \mathrm{H}$-NMR and GPC of PEUR-SS ${ }_{x}$-Ls, Raman spectroscopy of the other PEUR-SS ${ }_{x}$-Ns, DSC of PEUR-SS ${ }_{x}$-Ns, Stress-strain curves of selfhealing tests for the other PEUR-SS $-\mathrm{Ns}$, DMA of PEUR-SS $12 \%-\mathrm{N}_{3}$ and PEUR-BD-N $\mathrm{N}_{6}$, dual-shape memory effect of PEUR-SS $\mathrm{S}_{12 \%}-\mathrm{N}_{3}$, shapememory effect of PEUR-SS ${ }_{12 \%}-\mathrm{N}_{5}$, and dual-shape memory effect of PEUR-SS ${ }_{12 \%}-\mathrm{N}_{4}$ after recovery and self-healing.

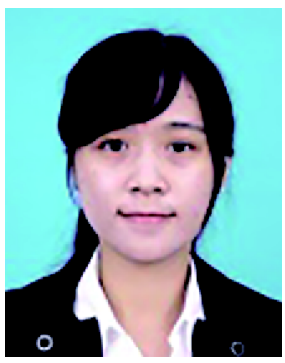

Xiao-Ying Deng received her bachelor degree in applied chemistry from Southwest University in 2015. Now she is a Master candidate in polymer chemistry and physics under the supervision of Professor Ke-Ke Yang at Sichuan University. Her research interests are related to the preparation and properties of shape-memory or self-healing polymers.

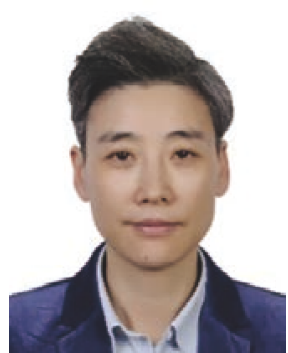

Ke-Ke Yang received her BSc degree in polymer materials (1994), MSc degree in chemical fiber (1997), and PhD degree in material science from Sichuan University in China. She joined Sichuan University in 1997, and now is a full professor in polymer chemistry and physics. Her research is focused on biodegradable polymers, polymer composites, shape-memory polymers and self-healing materials.

\section{基于二硫键的聚氨酯网络: 从可调多重形状记忆性能到同步修复}

邓小莹, 谢辉, 杜澜, 范诚杰, 成川颖, 杨科珂 ${ }^{*}$, 王玉忠

摘要 随着智能化时代的迅速发展，具有多功能或多响应的智能材料受到高度关注. 但如何将多个智能单元以协同模式结合到单一系统 中仍是研究者面临的巨大挑战. 本文设计合成了一种新型聚氨酯动态交联网络，该材料能够以独立的方式和协同作用模式呈现形状记忆 效应和自修复效应. 为了实现这一目标, 本文选择了聚四氢呋喃作为软链段以确保聚合物链具有良好的运动性, 同时将动态共价键二硫键 引入聚氨酯的主链中以实现材料在温和条件下的自修复. 此外, 通过有效调节二硫键含量、交联度和网络结构, 获得了较宽的玻璃化转变 温度 $\left(T_{\mathrm{g}}\right)$, 使网络具有两重、三重甚至四重形状的记忆效应. 在此基础上, 利用该材料的形状回复和修复的外界刺激条件的高度吻合, 同时 实现了材料修复和回复, 拓宽了材料的应用范围. 